\title{
Exploring (the Poetics of) Strange (and Fractal) Hypertexts
}

\author{
Charlie Hargood, David E. Millard \\ Matt R. Taylor \\ School of Electronics and Computer Science, \\ University of Southampton, UK \\ \{cah07r, dem, mrt\}@ecs.soton.ac.uk
}

\author{
Rosamund Davies \\ Samuel Brooker \\ School of Humanities and Social Sciences, \\ University of Greenwich, UK \\ \{R.Davies, S.Brooker\}@greenwich.ac.uk
}

\begin{abstract}
The ACM Hypertext conference has a rich history of challenging the node-link hegemony of the web. At Hypertext 2011 Pisarski [12] suggested that to refocus on nodes in hypertext might unlock a new poetics, and at Hypertext 2001 Bernstein [3] lamented the lack of strange hypertexts: playful tools that experiment with hypertext structure and form. As part of the emerging Strange Hypertexts community project we have been exploring a number of exotic hypertext tools, and in this paper we set out an early experiment with media and creative writing undergraduates to see what effect one particular form - Fractal Narratives, a hypertext where readers drill down into text in a reoccurring pattern - would have on their writing. In this particular trial, we found that most students did not engage in the structure from a storytelling point of view, although they did find value from a planning point of view. Participants conceptually saw the value in non-linear storytelling but few exploited the fractal structure to actually do this. Participant feedback leads us to conclude that while new poetics do emerge from strange hypertexts, this should be viewed as an ongoing process that can be reinforced and encouraged by designing tools that highlight and support those emerging poetics in a series of feedback loops, and by providing writing contexts where they can be highlighted and collaboratively explored.
\end{abstract}

\section{Categories and Subject Descriptors}

H5.4 [Hypertext/Hypermedia]: Theory.

\section{General Terms}

Design, Human Factors

\section{Keywords}

Strange Hypertext, Fractal Narratives, Hypertext Poetics.

\section{INTRODUCTION}

Concern over the preeminence of the node-link model in hypertext is a recurrent theme in the hypertext community. At Hypertext 2011 Pisarski [12] explored and advocated the possibilities of new approaches to hypertext: moving away from the topographical paradigm, or even spatial hypertext, to other forms that would prioritize the node as much as the link. Such forms, he speculated, would unlock a new poetics of hypertext.

Ten years previously, in Hypertext 2001, Bernstein noted a dearth

Permission to make digital or hard copies of all or part of this work for personal or classroom use is granted without fee provided that copies are not made or distributed for profit or commercial advantage and that copies bear this notice and the full citation on the first page. To copy otherwise, or republish, to post on servers or to redistribute to lists, requires prior specific permission and/or a fee.

$H T$ '12, June 25-28, 2012, Milwaukee, WI, USA.

Copyright 2012 ACM 1-58113-000-0/00/0010 ..\$10.00. of strange hypertext, and presented two exotic tools for hypertext - Card Shark, based on a card playing metaphor and Thespis, a kind of virtual play. Ten years previously to that, in 1991, Halasz delivered a keynote calling for an end to the 'Tyranny of the Link' [6], a theme revisited a few years later by Hall et al. when they identified the button as something that could be replaced with a more dynamic open model [7].

We are currently engaged in an ongoing effort to establish a community of writers and technologists who wish to explore strange hypertexts ${ }^{1}$. In this paper we set out an early experiment we have conducted to explore what effect an exotic hypertext structure has on writing: would writers engage with the structure and incorporate it into their stories, and might it result in the emergence of new poetics as predicted by Pisarski?

The vehicle for our work was a small hypertext engine that runs Fractal Narratives. These are hypertexts where the reader drills down into the text in a reoccurring pattern, rather than navigating between texts using links. The interface is one of fluid links [14], with the text appearing in-line as the reader navigates. The tool was introduced through a number of structured sessions to media and creative writing undergraduates, and the experience evaluated afterwards through focus groups and qualitative and quantitative analysis of their work.

\section{BACKGROUND}

In her recent book The Possible Worlds of Hypertext Fiction, Bell [2] echoes the words of many commentators, when she states that hypertext fiction 'might not constitute a radically new literary genre... but rather that it adds new dimensions to fictional selfreflexivity', already associated with postmodernist print fiction.

Since this association was established in the late 1980s and early 1990s, postmodernist aesthetics have become commonplace in mainstream culture, from the networked identities of Facebook [3] to the fragmented, non-linear and self-reflexive storytelling of film directors such as Tarantino (Pulp Fiction 1994 US), Nolan (Memento 2000 US) and Iñárritu, (Amores Perros 2000 Mexico, 21 grams 2003 US, Babel 2006 US). However, hypertext fiction itself does not seem as yet to have hit the mainstream. Bernstein [4] has suggested that it is, in fact, precisely hypertext fiction's early association with a particular moment of literary postmodernism, which now risks historicising it as a genre and limiting its potential to develop as a contemporary form, to expand its audience, its cannon and its range of storytelling [5].

Bernstein's suggestion is that more efforts should be concentrated on exploring where hypertext fiction should go next. There are many potential avenues for exploration and innovation. These include the platforms and the tools available, as well as potential narrative poetics, forms and techniques. Pisarski suggests one

\footnotetext{
${ }^{1}$ www.strangehypertexts.org
} 
potential avenue when, in contrast to a more usual focus on the link, he advocates a 'poetics of a hypertext node' as an approach to both analyzing and potentially inventing 'hypertext-friendly plots' [12].

Bernstein coined the phrase Strange Hypertext in 2001 to describe hypertexts that pushed beyond the standard node-link model [3]. Although non-node-link hypertext systems did exist, notably the spatial hypertext pioneered in systems like VIKI and VKB [10], Bernstein's argument was that modern Rapid Application Development (RAD) techniques made it possible to explore more playful forms much more easily than ever before. As an example he presented Card Shark, a story that is read by playing story cards in a sequence, and Thespis, a scripted play unfolding in a virtual space that the reader can explore at will. The ideas around Card Shark were later extended and the form described as Sculptural Hypertext [13] - because in practice all links (cards) are originally available, before being carved away according to the rules of the cards already in play.

Despite the acceleration of the RAD techniques highlighted by Bernstein, and the ubiquity of the web as a platform, strange hypertexts have still not really been the subject of any significant analysis in the hypertext community. The Strange Hypertext community was formed out of the Narrative and Hypertext Workshop at Hypertext $2011^{2}$. Its ambition is to explore exotic hypertext tools, and to find, promote and create new and unusual hypertext forms.

\section{FRACTAL NARRATIVES}

Fractal Narratives are based around the principle that any two consecutive text nodes in a story can be extended by adding a third optional text node between them. By applying this principle recursively, inserting further text nodes between the new element and the originals, an author can subdivide nodes with potentially infinite level-of-detail. Assuming that the transitions between each text node are seamless, the story can then be arbitrarily scaled without significantly affecting the flow or cohesion of the narrative as a whole. Since individual sections of the narrative can be extended independently, the reader maintains complete control over the level-of-detail of all aspects of the story. The idea was to explore a different aesthetic to that of node-link narratives. Aarseth has characterized the reader experience of the latter as 'the jump' - the sudden displacement of the user's position in the text.' [1] Fractal Narratives remove this experience of displacement, focusing instead on the effects of the contextual regulation of connectivity and autonomy between nodes [12], such as both disorientation and amplification.

Treating the static start/end nodes (see fig 1) as necessarily privileged frame elements (that still form part of the text), the rest of a fractal narrative comprises a binary tree stored as an XML document. A key motivation when creating the authoring tool was to conceal the underlying complexity of the system from the (nontechnical) users and present a simpler interface that conformed more to their expectations of a writing tool. The user is able to extend the story by clicking on placeholders, which indicate areas of the narrative where new text nodes can be inserted. This in turn brings up a text entry box, allowing the user to write and edit the story content in place. JavaScript is utilized to handle the insertion and deletion of text nodes and placeholders without requiring the page to reload and thus interrupt the authoring process. Since the

\footnotetext{
${ }^{2}$ http://nht.ecs.soton.ac.uk/2011

${ }^{3}$ http://www.ryman-novel.com/
}

whole structure remains in view throughout the authoring process there is no bias towards depth or breadth, and authors are free to create symmetric or non-symmetric trees as they prefer.

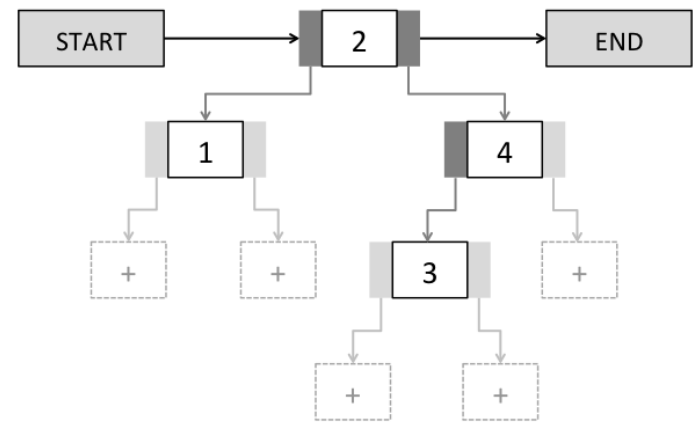

Figure 1: Example Fractal Narrative Structure; in expanded form the nodes are read in the order START, 1, 2, 3, 4, END

\subsection{Experiment Aims and Methodology}

In order to test its ease of use and appeal to a general user, and avoid preconceptions about hypertext style and form, it was decided to give the Fractal Narratives tool to writers who had experience of both creative writing and consumer digital platforms, but no established assumptions about the kind of storytelling suitable to hypertext.

The tool was given to media and creative writing undergraduates as a 3 week section of a module, Writing the Digital Self, which formed part of the second year of a 3 year UK BA (Hons) Degree, comprised of four modules of study a year. The participants had been introduced to the hypertext novel $253^{3}$ as part of this module. However they had no other experience as readers or writers of hypertext fiction. Depending on the individual, their prior writing experience was in some or all of: prose; poetry; journalism; stage and screen writing. The tool was explained to them through a short verbal presentation, with visual projection of the site. They were asked to read through the information on the site, to begin with the two initial nodes, add an initial 'middle' node in the first week and then to develop the story over the next two weeks. This activity formed part of a log book of weekly assignments for the module. The participants gave feedback in the form of both written questionnaires and a group discussion, which was transcribed.

\subsection{Experiment Findings}

Having completed the experiment there are both some quantitative and qualitative observations we can make.

\subsubsection{System Usage}

We are able to make some observations about the way the students used the system. In total 43 users signed up, of which 41 created a story, and of those 36 created a story that went beyond the mandatory 2 initial nodes and actually included some 'fractal nodes' (nodes not a start or end). Of those participants that utilized the fractal nature of the system we have compiled some basic average usage statistics, as displayed in Table 1 .

Table 1. Average statistics for stories of more than 2 nodes.

\begin{tabular}{|c|c|c|c|}
\hline No. Nodes & $\begin{array}{c}\text { Max Node } \\
\text { Depth }\end{array}$ & $\begin{array}{c}\text { Average } \\
\text { Node Depth }\end{array}$ & $\begin{array}{c}\text { Average Node } \\
\text { Length }\end{array}$ \\
\hline 5.4 & 2.9 & 1.2 & 97.4 \\
\hline
\end{tabular}


Table 1 shows us that the users generally created mostly very short stories (averaging less than six nodes per story), and that individual nodes were also quite short (averaging less than 98 characters). It also shows an average maximum depth (maximum levels below the initial beginning and end nodes) of 2.9 and an average overall depth of all nodes in the story of 1.2.

We can further explore this by examining the features of nodes at different depths within the story to understand how the users had utilized the fractal nature of the system. This is displayed in Table 2 , with data for each level of depth covering frequency and length (in characters). It is to be noted that this table excludes stories that didn't use that fractal nature of the system and only comprised of the mandatory start and end nodes.

Table 2. System Usage: statistics for nodes of different depths.

\begin{tabular}{|c|c|c|c|c|}
\hline Depth & $\begin{array}{c}\text { Frequency } \\
\text { of Nodes }\end{array}$ & $\begin{array}{c}\text { Average } \\
\text { Node } \\
\text { Length }\end{array}$ & $\begin{array}{c}\text { Node } \\
\text { Length } \\
\text { Min }\end{array}$ & $\begin{array}{c}\text { Node } \\
\text { Length } \\
\text { Max }\end{array}$ \\
\hline 0 & 72 & 78.3 & 3 & 466 \\
\hline 1 & 36 & 96.3 & 23 & 337 \\
\hline 2 & 48 & 115 & 18 & 507 \\
\hline 3 & 24 & 97.5 & 19 & 457 \\
\hline 4 & 8 & 122.9 & 32 & 444 \\
\hline 5 & 2 & 98.5 & 41 & 156 \\
\hline 6 & 2 & 117.5 & 75 & 160 \\
\hline 7 & 1 & 170 & 170 & 170 \\
\hline
\end{tabular}

From this data we find that over a third of the nodes are made up of the start and end nodes (depth 0). We also find that these nodes are on average the shortest, with users going into greater levels of detail within fractal nodes than start/end nodes. Excluding the depth 0 nodes the most common 'fractal node' depth is 2 which also represents a depth with a rise in length. It is possible that users use the first two depths $(0$ and 1$)$ to write short plot structural milestones for beginning, middle, and end, rather than going in to any detail. This would explain why these nodes are generally shorter than the mean length for nodes overall.

\subsubsection{Resulting Works}

Since the narratives were all quite short, only a few of them really explored the notion of detail and depth as originally envisaged. One example is provided by Triple Indemnity (Figure 2), which, riffing on a noir theme, begins with a pregnant moment: 'It was a rainy night. It was time to make my move' and then expands it. First greater detail is provided on the setting: 'Every droplet of water that cascaded down the windows was rattling their panes.' Then it is possible for the reader to open up the story at different points, both to expand the thoughts of the narrator and to connect to different time frames (see Figure 2). Another narrative, Can't Stop, generated depth through the exploration of multiple perspectives on a situation. Such narrative strategies are not dissimilar to those of node-link hypertext fiction, which also frequently brings together different and discontinuous time frames and perspectives. Those participants' narratives which focused on a chronological unfolding of continuous time, on the other hand, functioned less well as fractal narratives, since the opening up of nodes served rather to fill in gaps in the story, than to drill down into it and expand it in depth.
It was evident, in fact, that some of the narratives were not operating according to fractal logic at all, but according to other organizing principles. Many of the narratives in fact had a linear structure. The reader was not offered any choice as to what node to click, but, having read the initial two nodes and opened the third node, was then directed on a path through a linear story. In several of the narratives this progression was structured so as to provide successive revelations and reversals and/or to put a new spin on the ending, which the reader had already read. Other narratives experimented with different approaches to non-linear storytelling, sending the reader on a path which moved backwards and forwards through the events of the story.

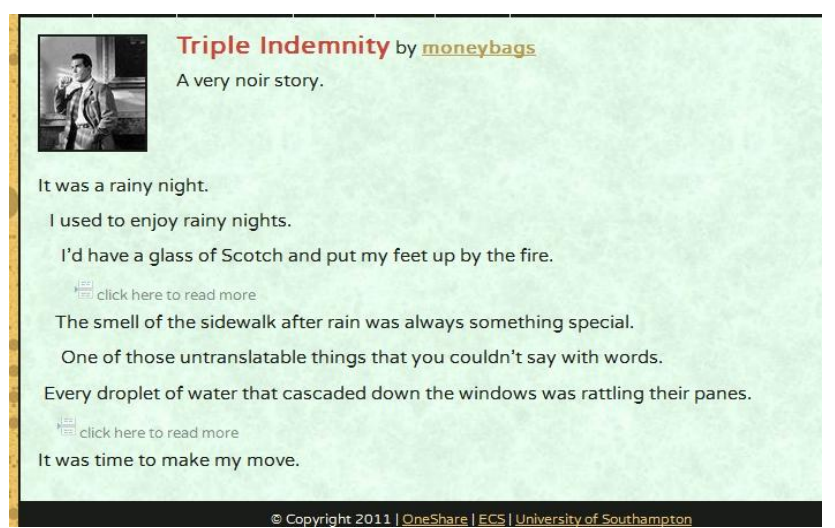

Figure 2: The Fractal Narrative Tool showing expansions on the story 'Triple Indemnity'

Rather than exploiting the storytelling potential of fractals or depth, both the linear and nonlinear storytelling examples described above thus pick up instead on the potential for 'hooking' a reader with the beginning and end of a story and gradually unfolding to him how the former led to the latter. This focus on the how and the why, rather than the what is a feature of many contemporary cinematic narratives, in which non-linear and multiple perspective storytelling techniques are employed to unfold what is ultimately a closed and linear text. Such cinematic narratives were indeed explicitly referenced by the participants in their discussion of their own stories. This will be expanded on in the next section.

An important effect of the Fractal Narratives structure then is that, having opened up all the nodes, the reader is presented with a complete and unified text, in a linear arrangement, which she is able to compare with the non-linear, fragmented and possibly confusing or tortuous ways in which she has read it. This may also then encourage her to return to an earlier, unexplored node after uncovering a clue in a subsequent one. Thus, although the narrative strategies that appeared most successfully to explore depth in the fractal narratives discussed above, such as different time frames and points of view, are familiar from existing hypertext fiction, Fractal Narratives nevertheless provide a very different reader experience to that of node-link hypertext fiction. However, we would argue, it is still potentially a multilinear one.

Although Aarseth [1] states that a narrative, which describes a sequence of events non-sequentially, but in a linear arrangement of text, cannot be called a non-linear text [5][9], we would argue that, since Fractal Narratives make it possible to offer readers a choice of how to read the story, their poetics complies with Ensslin's statement that 'hypertexts defy the macrostructural monolinearity and hierarchies of the majority of literary print media, as the order and selection of text units varies from reader to reader and from reading to reading' [5]. The characteristic 
hypertext fiction reader's experience of only having a glancing view, of never having the complete story [8], [11] is also conceivable in a large scale fractal narrative, (although the narratives involved in this particular experiment were all quite short, meaning that all the nodes could quite quickly be opened by a reader in one sitting, even though the order of opening would still vary each time).

We would suggest therefore that Fractal Narratives are nonlinear or multilinear texts, but, while their poetics is multilinear, it is not one of discontinuity or 'the jump'. The idea is rather that a fractal narrative offers the potential of expanding (and potentially contracting) a narrative in the same way that one might zoom in on an image to reveal further detail and more dimensions, while nevertheless continuing to view the same image. This seems to us to be a valid and potentially productive addition to hypertextual techniques and aesthetics.

\subsubsection{Participant Responses}

\section{The Poetics of Fractal Narratives}

The majority of the participants did not however seem to be particularly inspired by the potential of fractals as a poetic device, despite the fact that this was explained to them on the website and that some said they did understand the concept. In discussing their experience of writing and reading the Fractal Narratives, participants put more emphasis on the possibilities offered by the way that the narratives hook the reader with both beginning and end of the story and then allow him to explore how the one led to the other. They cited Pulp Fiction (Tarantino 1994), Memento (Nolan 2000) and Eternal Sunshine of the Spotless Mind (Gondry 2004) among others, as examples of narratives, which worked in similar ways. This emphasis suggests that the majority of the participants were in fact writing and reading the Fractal Narratives as linear texts, which employed non-linear storytelling techniques, like the cinematic narratives they cited, narratives which, as discussed above, Aarseth [1] rules out from being nonlinear or multilinear texts. The participants' interpretation of the tools thus corresponded to the kinds of narratives and modes of narration that the participants were already familiar with, rather than to the intentions of the tool's designers. Thus, although they were enthusiastic about non-linear storytelling and their writings and readings opened up some unexpected insights, the participants' unfamiliarity with non-linear texts also limited their ability to exploit the potential of Fractal Narratives. It was nevertheless clear that participants' experimentation had developed their understanding and piqued their interest, introducing them to new ideas, such as the importance of the kind of 'contextual regulation' of nodes identified by Pisarski [12]. The latter's discussion of the tension between connectivity and autonomy in the content of nodes and how this functions as a hypertextual narrative device finds its counterpart in the participants' similarly themed discussion of the need to keep the content of the nodes 'open ended':

Participant A: '...you kind of had to have it a bit open ended in a way because then you might want to add a line between the middle and the first line. So it had a narrative, but it had to be a bit vague...it was interesting,

However participants also said that the one line text entry boxes of the display made them conceive of their stories in one line sentences. Many seemed paradoxically to understand Fractal Narratives as exercises in simplicity and conciseness, rather than in exploring detail and depth.
It is also possible that the representational conventions of the Fractal Narratives authoring tool encouraged the participants' tendency to follow linear narrative strategies, since the nodes in the authoring interface were organized in a linear visual display, rather than represented in a branching structure.

\section{Reading/Writing}

As Landow [8] and Aarseth [1] point out, the poststructuralist elision of the boundary between writing and reading is an unavoidable reality of hypertext fiction. Critics of hypertext, have to acknowledge their own investment in and construction of the narrative in very concrete ways, and also the fact that they can achieve only a partial rather than an exhaustive reading. The text is thus both unstable and inexhaustible.

In the Fractal Narratives experiment, participants recounted feelings of both pleasure and anxiety in their acknowledgement of this instability and the particular dynamic between writer and reader. One recurring trope of discussion was around their desire to receive feedback on what they had written. For one participant, this needed to be in the form of collective authoring.

Participant L: '...people should be able to add to your story to see how it could evolve...That would definitely have been more fun. Because you'd be checking up on it. You'd be seeing 'oh what's happened...",

Her view was shared by others. Some said they wanted to have the option to write both single author and collective narratives or to be able to keep intact both an original core text and its expanded collective version. Others simply wanted readers to be able to post comments. Overall, there was a strong sense expressed by the group, in line with the practices and conventions of social media, that online writing necessitated a rapid and explicit feedback loop between writer and reader, in way that print based writing did not. They expressed disappointment that this was not forthcoming on the Fractal Narratives site. One participant, drawing on the traditional paradigm of the writer as sole author, expressed concern about losing control of his text if the distinction between reader and writer was elided. Other participants, however, were more concerned about their lack of control as writers in relation to the technology. They felt that the Fractal Narratives authoring tool to some extent dictated the way that they wrote, which led to feelings of anxiety and frustration.

Participant G: 'I just found myself less in control of what the story was, because I was trying to fit it onto what the previous or the next sentence was going to be, which I didn't like because I like to be in control and I didn't feel I was.'

A sense of rising panic for the writer stemmed from the fact that, each time he or she created a new node in the authoring tool, two more empty nodes would open up in a never ending process of empty boxes to be filled. Thus what became the chief source of pleasure for the reader was a major source of stress for the writer. Several participants said the reason that they confined their stories to short sentences was that they felt that this would make the contextual regulation of the nodes easier.

\section{Narrative and Structure}

Conversely some participants said they thought the authoring tool would work well as a more general planning tool for writers, because, by encouraging the writer to start with beginning and end and expand the middle, it put more overt emphasis on structure than they were used to when writing short stories.

Participant $\mathrm{H}$; '... if you don't use it for...well, as its original purpose... it would actually be a good way of writing a story and 
you could just take out paragraphs without having to delete them and you could just see how your story works.'

This emphasis on structure is in fact the standard approach in screenwriting practice, where writers tend to comprehensively plan a story, beginning to end, scene by scene, before starting to write a script. In screenwriting, where words metamorphose into images on screen, structure is treated as the essential storytelling material. In prose narrative, on the other hand, great emphasis is laid on the choice and arrangement of words themselves. Those students who did not study screenwriting said they were not used to planning their stories structurally, but to a more spontaneous (and linear) development:

Participant H: 'Normally you just write stories as you're going along, rather than think about the beginning and then jump straight to the end.'

Both hypertext and screenwriting are modes of writing where meaning is created through structure, to the extent that narrative development by the writer requires detailed and formal structural planning. This would seem to explain both why participants looked to cinematic narrative for models in their work and why they had problems with the fractal narrative tool. Participants' difficulties with the tool and sense of being out of control appeared to be down in part to the fact they did not attempt to map out a structure first, but tried instantly to arrive at the exact and final formulation of words in each text box as they went along. A more fruitful approach might have been to first plan the movement and dimensions of the story, node by node, then go back and decide on the final choice of words. Participants expressed the view that, while taxing, this approach could potentially bring beneficial rigor and clarity to their writing.

\section{CONCLUSIONS}

Our experiment with Fractal Narratives developed an innovative hypertext tool, using fluid links [14], which non-technical users could manipulate through a simple interface and which they found easy to use to create and instantly publish narratives. However, at the same time, by concealing the underlying structure of the hypertext, the interface also appears to have limited writers' control and understanding of the tool. This problem was exacerbated by the fact that most of the writers were unused to thinking structurally about their writing in the first place.

Here is one point at which the blurred distinction between hypertextual reading and writing comes into focus. The multilinear or antilinear [5] structure of hypertext fiction has often been contrasted with the necessarily linear nature of the reader's journey through it [5] [9]. To come at this logic from the other direction, reading a hypertext may be a linear journey, but writing it cannot be. Taking into account the fact that writers need to grasp the non-linear structure they are working with, in its next iteration our authoring/publishing tool needs to identify more fully the points of overlap and divergence between how one might write a fractal narrative and how one might read it. Our study also raises the question of the role that an authoring tool might and should play in helping writers to acquire the particular skillset necessary to a particular genre of writing; skillsets traditionally required through reading relevant work by other writers.

This is therefore both an authorial and technical challenge. In terms of authoring, our experiences have given us ideas about how to guide and workshop with writers new to hypertext fiction in order to help them understand and explore the potential of Strange Hypertexts. In the context of Fractal Narratives, we would aim to explore with them first the notion of depth and detail as narrative devices and as part of different narrative aesthetics, considering models from both print and digital fiction, as well as some specific fractal examples and giving more time for experimentation and opportunities for collaboration and feedback between writers and readers. While, on the technical side, the authoring tools need to interpret these emerging poetics into layout and vocabulary that encourages authors to think about structure before they begin writing: emphasizing depth visually, showing levels and symmetry more clearly, or creating workflow that separates structural construction from actual writing.

In our work we set out to investigate strange hypertexts and analyze the emergent poetics of Fractal Narratives. Our early experiment has shown that while poetics do start to emerge, this is an ongoing cycle and must be reinforced with tool/interface development and appropriate learning contexts. By being aware of and understanding these poetics as they emerge from real use we believe we can begin to tutor new writers more successfully, and design authoring tools that encourage authors to build on the strengths of strange forms.

\section{REFERENCES}

[1] Aarseth, E. J. in Hyper/text/theory (ed. George Landow) Baltimore: John Hopkins University Press, 1994,.

[2] Bell, A, The Possible Worlds of Hypertext Fiction, Basingstoke: Palgrave Macmillan 2010

[3] Bernstein M. 2001 Card shark and thespis: exotic tools for hypertext narrative. In Proceedings of the 12th ACM conference on Hypertext and Hypermedia ACM, New York, NY, USA, 41-50.

[4] Bernstein M. 2011. Wandering Monsters! on the problem of coherent hypertext narrative. In Proceedings of the Narrative and Hypertext Workshop at ACM Hypertext 2011.

[5] Ensslin, A, Canonizing Hypertext, London: Continuum 2007

[6] Halasz, F. G. 1991. "Seven issues": Revisited. Closing plenary address. In Proceedings of ACM Hyper-text '91 Conference, San Antonio, Texas, December 18, 1991.

[7] Hall, W. 1994 Ending the Tyranny of the Button. IEEE Multimedia, 1 (1). pp. 60-68.

[8] Landow, G. P. 'What's a Critic to Do?: Critical Theory in the Age of Hypertext' in Hyper/text/theory (ed. George Landow) Baltimore: John Hopkins University Press, 1994.

[9] Liestøl, Gunnar, Wittgenstein, Genette and the Reader's Narrative in Hypertext in Hyper/text/theory (ed. George Landow) Baltimore: John Hopkins University Press, 1994.

[10] Marshall, C. C., Shipman III, F.M. \& Coombs, J.C., 1994. VIKI: spatial hypertext supporting emergent structure. In Proceedings of the 1994 ACM European conference on Hypermedia technology ECHT 1994. ACM Press, pp. 13-23.

[11] Murray, J, Hamlet on the Holodeck, Cambridge, Mass.: MIT Press 1997

[12] Pisarski, M, 'New Plots for Hypertext? Towards Poetics of a Hypertext Node'. Hypertext 2011

[13] Weal, M. J., Bernstein, M. and Millard, D. E. 2002 On Writing Sculptural Hypertext. In: The Thirteenth ACM Conference on Hypertext and Hypermedia, June, Maryland, USA. pp. 65

[14] Zellweger, P., Chang, B., Mackinlay, J.D. 1998. Fluid Links for Informed and Incremental Link Transitions. ACM Hypertext 1998: pg 50-57 